Resumo

Este artigo tem como objetivo discutir aspectos relacionados ao encontro mãe-bebê no pós-parto. $O$ nascimento e a recepção do bebê que chega são, em geral, descritos pela mãe como um momento de profunda alegria e sensação de completude. Partindo do princípio de que raramente as dificuldades vividas aparecem no discurso materno, temos como proposta discutir o que está por trás da negação da dor e das dificuldades, que também se fazem presentes nesse momento. Assim, pretende-se retomar aspectos do pensamento psicanalítico relacionados à constituição e à organização do psiquismo do bebê, no intuito de compreender mais profundamente a complexidade presente no nascimento, tanto do ponto de vista da mãe quanto do bebê.

Descritores: mãe-bebê; depressão pós-parto; ambivalência.

\section{ENCONTROS E DESENCONTROS: DO NASCIMENTO À CONSTITUIÇÃO DO PSIQUISMO}

\author{
Paula Cristina Nogueira Vieira Komniski \\ Daniela Scheinkman Chatelard \\ Isalena Santos Carvalho
}

DOl: http//dx.doi.ors/10.11606/issn.1981-1624.v22i1p113-131.

no momento em que a boca encontra o seio, ela encontra e absorve um primeiro gole do mundo. Afeto, sentido, cultura estão co-presentes e são responsáveis

pelo gosto das primeiras gotas de leite que o infans

toma. A oferta alimentar se acompanha sempre da absorção de um alimento psíquico, que a mãe interpretará como absorção de uma oferta de sentido. Assistiremos perplexos à metamorfose que sobre ela operará o originário (Aulagnier, 1979, p. 40).

- Doutoranda no Programa de Pós-Graduação em Psicologia Clínica e Cultura da Universidade de Brasília, Brasília, DF, Brasil.

- Doutora em Psicologia Clínica e Cultura pela Universidade de Brasília, Brasília, DF, Brasil.

- a Doutora em Psicologia Clínica e Cultura pela Universidade de Brasília. Professora adjunta do Departamento de Psicologia da Universidade Federal do Maranhão, São Luís, Maranhão, Brasil. 


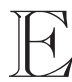

ste artigo é fruto de uma experiência clínica marcada pelo atendimento de crianças, assim como de mães e bebês recém-nascidos. Dificuldades no pós-parto relacionadas à depressão e problemas para amamentar e acolher bebês sindrômicos têm sido uma constante nos consultórios de profissionais interessados em trabalhar e compreender melhor questões relacionadas à primeira infância.

O discurso de inúmeras mães, ao longo de muitas entrevistas antes do início do trabalho analítico, levou-nos a desejar compreender o que esse bebê que chega traz consigo: Onde inicia sua pré-história? Como se constrói a espera dos pais? Qual a relação entre o bebê que chega e o que se espera (ou não se espera) dele? 'Tais questões nos aproximam de uma reflexão freudiana quando, ainda em 1905, o autor anuncia que "o encontro do objeto é, na verdade, um reencontro" (Freud, 1905/1996, p. 99).

A chegada de um bebê ao mundo é sempre descrita com tons fortes de emoção. Por vezes, observa-se a dificuldade das mães em colocar em palavras a experiência do encontro com o filho recém-nascido. Seja por se tratar de um tempo da vida em que, por parte do bebê, ainda não existem palavras, seja devido ao impacto emocional - além da extenuação física vivenciada pela mãe -, o fato é que essa experiência é sempre descrita de forma superlativa. Além disso, é possível observar que o discurso materno ressalta, invariavelmente, os aspectos positivos e a alegria de poder acolher o bebê que chega: criança "portadora de esperança", que suscita na mãe "amor incondicional", "desejo de acolher e proteger", "sentimento de plenitude nunca antes experienciado".

Tais relatos parecem conduzir-nos a conceber o amor materno como sendo da ordem do instinto, ou seja, movido por manifestações instintivas: esta mãe seria naturalmente impelida a se ocupar do bebê que traz à luz. Tal afirmação parece contraditória se considerarmos o fato de que muitas crianças são abandonadas ao nascer e, por vezes, em condições muitíssimo adversas, como bebês deixados no lixo, "jogados fora".

Ao levarmos em conta essas situações, aproximamo-nos da ideia de que a maternidade, no humano, deve ser compreendida como sendo da ordem da adoção: ou seja, o bebê que nasce deverá ser adotado - gesto que só ocorre na medida em que ele e a mãe se encontram e passam a se conhecer. Da mesma maneira, a mãe que acolhe, cuida e se ocupa do bebê, também deverá ser adotada pelo filho.

Essas reflexões nos remetem à afirmação impactante de Winnicott (1945/2000), ao dizer, diante da Sociedade Britânica de Psicanálise, que: "there is no such a thing as a baby" [não há nada como um bebê]. O impacto produzido pela

114 Estilos clin., São Paulo, v. 22, n. 1, jan./abr. 2017, 113-131. 
maneira como o autor faz tal afirmação nos convida a compreender que a existência do bebê só poderá ser garantida a partir do endereçamento do adulto que olha, enxerga, nomeia e banha de palavras.

Ao partirmos do princípio de que, como afirma Badinter (1980/1985), existe um mito em torno do amor materno, faz-se necessário rever alguns elementos fundamentais relacionados ao nascimento e ao encontro mãe e bebê. Ao darmos crédito e lugar para o significado da linguagem no humano, responsável por aquilo que a psicanálise denominará de inconsciente, seremos impelidos, inevitavelmente, a observarmos a complexidade da maternidade e da relação que se construirá entre a díade que acaba de se encontrar e que trilhará junta um longo percurso.

Com o avanço dos estudos sobre o autismo desenvolvidos por Kanner na década de 1950 e, no mesmo período, com as pesquisas de Spitz, que culminam com os conceitos de depressão anaclítica e hospitalismo, observamos, a partir de então, que passa a ser concedido ao bebê o direito ao sofrimento psíquico e, consequentemente, à loucura (Golse, 2003). Assim, pode-se afirmar que, a partir desse período, a psicanálise passa a adotar um novo paradigma, ou seja, a criança passa a ser olhada não somente de uma perspectiva edípica, metaforizada por seu lugar na cama dos pais, mas os olhares passam a se voltar também para o bebê no colo da mãe.
A partir de tais considerações, é possível afirmar que, com o nascimento de um bebê, nasce uma mãe e um pai, mas algumas coisas também morrem: morre o estatuto de liberdade de um casal, morre a condição única de filha e de filho para que assumam também a condição de pais, e morre o bebê idealizado ao longo da gestação, que não coincide com aquele que acaba de chegar. Para Stern (1995/1997), é preciso que a mãe recém-nascida abandone boa parte das antigas fantasias que guardava relacionadas a reparar, corrigir e mesmo refazer sua infância. É preciso, inclusive, segundo o autor, abandonar a ideia de que é possível retornar a esta infância. "Um mundo (mesmo que parte dele seja ilusão) se foi. E geralmente existe um profundo senso de perda subjacente ao senso dos mundos que foram ganhos" (Stern, 1995/1997, p. 29).

Vamos, assim, nos aproximando da complexidade que envolve a forma como o bebê irá se organizar psiquicamente: fruto de uma história anterior a sua própria concepção, é somente pelo investimento do outro que poderá sobreviver e se organizar psiquicamente. Para tanto, é preciso que a mãe se disponibilize a receber o bebê que encontra, elaborando o luto do filho imaginário, idealizado durante a gestação. Além disso, ela precisa de tempo para ressignificar seu lugar e seu novo papel, tudo isso associado aos cuidados que deve oferecer ao bebê.

Dessa maneira, compreendemos a importância de desenvolvermos 
um olhar atento e reflexivo para o momento do nascimento. Diante das reflexões anteriormente propostas, vemos que a chegada de um bebê traz, em sua essência, sentimentos paradoxais e ambivalentes, dificilmente explicitados: "culpa", "instinto maternal" e "amor incondicional" são termos sempre presentes. O superlativo e a dificuldade de colocar em palavras a experiência vivida nos oferecem elementos para questionarmos o que está em jogo no encontro da mãe com o bebê que chega. Aproximamo-nos, assim, da ideia de que o excesso de amor, de afeto, de emoção, a incondicionalidade dos sentimentos, o "instinto maternal" - termos bastante presentes no discurso das mães "recém-nascidas" - podem ser compreendidos como forma de sobrepor as dificuldades pelas quais a díade-mãe bebê pode passar.

Nesse sentido, este artigo tem como objetivo retomar aspectos do pensamento psicanalítico relacionados à constituição e à organização do psiquismo do bebê, no intuito de compreender mais profundamente a complexidade presente no nascimento, tanto do ponto de vista da mãe quanto do bebê. Para tanto, pretende-se retomar, de textos freudianos, momentos em que o autor apresenta, em seu pensamento, a importância da figura materna, que é única e primordial, responsável pelo acolhimento e pelo oferecimento do próprio ego ao bebê que acaba de nascer. 
Além disso, a partir dos anúncios freudianos, pretende-se avançar desde os chamados pós-freudianos (dentre eles Melanie Klein e Donald Woods Winnicott), até autores mais atuais, como Caroline Eliacheff e Myriam Szejer, que desenvolvem práticas de intervenção precoce em maternidades e UTIs neonatais. Muitos desses autores exercem a prática da psicanálise em contextos em que, do ponto de vista do bebê, a linguagem ainda não está instalada, mas, ainda assim, funciona como mediadora das relações, reduzindo os sintomas apresentados pelos bebês e por suas famílias.

Com a significação das experiências maternas e paternas que ainda não haviam recebido inscrição de linguagem e que, portanto, apareciam na forma de sintomas, a psicanálise contribui para que, a partir dessas intervenções, o bebê que acaba de nascer possa encontrar lugar para sua subjetivação e, consequentemente, para sua existência.

Winnicott (1949/2000) afirma que lhe agrada a ideia de que Freud se viu às voltas com a questão do nascimento, mas que não conseguia chegar a uma conclusão definitiva, uma vez que lhe faltavam dados importantes para uma reflexão mais aprofundada do problema. $\mathrm{O}$ autor comenta que as limitações freudianas têm relação com o fato de que sua prática clínica se deu, exclusivamente, com pacientes adultos. Assim, seria inevitável que, apesar de seus anúncios, lhe faltassem elementos centrais, originários de uma prática mais tarde desenvolvida, para que pudesse avançar sua pesquisa. "Ao refletirmos sobre o pensamento de Freud, portanto, deveríamos nos lembrar constantemente do que faria ele, um cientista, se estivesse hoje vivo e participasse ativamente do mundo psicanalítico, podendo levar em consideração os nossos conhecimentos sobre a primeira infância" (Winnicott, 1947/2000, p. 255).

Trazer à luz as possíveis dificuldades do pós-parto, observando atentamente a dinâmica psíquica vivenciada por essa díade pode ser relevante, uma vez que, ao reconhecermos e darmos lugar para o sofrimento psíquico já no início da vida, podemos trabalhar para compreender as possíveis origens de tais dificuldades e atuar no sentido de facilitar o encontro e o acolhimento do bebê e da mãe que acabam de nascer.

A psicanálise vem, ao longo das últimas décadas, atentando para a importância de uma observação cuidadosa da relação mãe-bebê como forma de compreendermos a organização psíquica e a ascensão do sujeito (Lacroix \& Monmayrant 1995/1997). Nesse sentido, 
considero relevante aprofundar a discussão sobre o que denominarei, neste trabalho, de encontro: um bebê que vem à luz e uma mãe que também nasce com a chegada do filho.

Freud desenvolveu sua prática clínica, bem como boa parte de seus escritos sobre a psicopatologia da vida adulta, relacionando-a às experiências infantis, mais especificamente no tempo da triangulação edípica. É importante salientar, no entanto, que em momentos-chave de sua obra o autor atenta para a importância e a singularidade da relação mãe-bebê como fundamental para a estruturação do sujeito. "Há bem mais continuidade entre a vida intrauterina e a primeira infância do que nos faz crer a notável ruptura do ato do nascimento. O objeto psíquico materno substitui, para a criança, a situação biológica do feto" (Freud, 1926/2014, p. 80).

Em outro momento importante de sua obra, Freud (1905/1996, p. 99) reconhece e valida a importância da figura materna para a estruturação psíquica do filho ao afirmar que

desses primeiros e mais importantes de todos os vínculos sexuais, resta, mesmo depois que a atividade sexual se separa da nutrição, uma parcela significativa que ajuda a preparar a escolha do objeto e, dessa maneira, restaurar a felicidade perdida. Durante todo o período de latência a criança aprende a amar outras pessoas que a ajudam em seu desamparo e satisfazem suas necessidades, e o faz segundo o modelo de sua relação de lactente com a ama e dando continuidade a ele.

Os anúncios freudianos sobre os momentos iniciais da vida do bebê e sua relação com a mãe apontam para a importância fundamental desse tempo da vida para a organização psíquica do humano. Inacabado desde o berço, é na relação primordial e fundante com a figura materna que o bebê adquire as primeiras experiências e toma, como afirma Aulagnier (1975/1979), citada na epígrafe deste trabalho, "os primeiros goles do mundo" e encontra, a partir daí, as bases para a estruturação de seu próprio psiquismo.

Freud, em "A interpretação dos sonhos", faz uso do termo "umbigo do sonho". É interessante considerar essa metáfora utilizada pelo autor justamente na obra que marca o nascimento da psicanálise. O termo é utilizado para referir-se a um ponto crucial, presente no conteúdo manifesto, localizando-o em um momento específico da experiência onírica: "esse ponto onde o sonho é insondável, onde se interrompe o sentido ou toda a possibilidade de sentido" (Freud, 1900/1996, p. 482). Como afirma Coutinho (2009, p. 3), para esse ponto o autor "escolheu 
uma palavra que se refere à fundamental relação entre mãe e filho, da qual todo ser humano leva no corpo uma cicatriz indelével". Umbigo: marca, símbolo, cicatriz que representa a separação do bebê de sua mãe, responsável pela primeira experiência de autonomia e também de dor: a primeira inspiração. Separado biologicamente da mãe, ele agora precisa respirar: primeiro gesto autônomo que o impulsiona à sobrevivência.

A interrupção de sentido seria o aspecto do sonho mais próximo àquilo que, como afirma Rennó (2012) não pode ser reconhecido. Esse ponto do sonho, afirma o autor, é constituído por uma massa de pensamentos que não podemos desmanchar e que, ao mesmo tempo, mantém um ponto de ligação com o resto do conteúdo do sonho:

um ponto de falha na malha que o constitui. Sem dúvidas, poderemos ver, neste ponto, a presença de um ponto de real, não simbolizado e que se coloca como opaco, demonstrando a existência de um ponto fora do sentido. É, exatamente neste ponto de real, neste ponto onde o sentido desaparece, ou melhor, onde o sujeito não pode ser reconhecido (Rennó, 2012, p.1).

A impossibilidade de reconhecimento do sujeito simbolizada, no sonho, justamente pelo umbigo, remete-nos ao momento do nascimento e nos convida a observarmos o bebê em sua condição de absoluta fragilidade e impotência frente ao choque vivenciado pelo corte daquilo que o unia à mãe. A ruptura do estado de autorregulação até então experimentado no interior da mãe pode ser compreendido como o que Aulagnier (1975/1979, p. 41) denomina de "vivência informulável, um x que, posteriormente, a linguagem designará como sofrimento.

Observa-se, dessa maneira, que, como o "umbigo do sonho", caracterizado por sua inacessibilidade, assim é o mundo para o bebê: ainda desprovido de sentido, a ser nomeado e apresentado pelo discurso materno para que possa ser encontrado. Ou seja, a perda de unidade na relação com a mãe, caracterizada pela vida intrauterina, impulsiona o bebê na busca de um sentido para essa nova forma de existência. Assim também é o sonho, que traz em si algo que se perdeu e que só poderá ser resgatado pela interpretação, ou seja, é somente na relação com um outro, que o sentido poderá ser encontrado e nomeado.

Retomar o texto freudiano sobre os sonhos é, também, retomar as origens da psicanálise. Ao buscar encontrar sentido nos próprios sonhos, Freud se depara com aspectos universais do inconsciente humano: é por meio do processo de autoanálise que o autor entra 
em contato com conteúdos infantis recalcados e que se atualizam nos sonhos, o que o permite compreender aspectos centrais de seu funcionamento psíquico. Em uma produção clínica e metapsicológica rica e reflexiva chega, ao longo dos anos, ao conceito de aparelho psíquico.

Pensar em aparelho psíquico nos remete, inevitavelmente, à fragilidade do bebê humano: com a caixa craniana aberta, imagem e condição representam o inconsciente a céu aberto - termo comumente utilizado para representar a psicose -, condição em que integração ou não integração se manifestam justamente na dificuldade de representação do próprio corpo como unidade, com bordas e delimitações que organizam e permitem a integração.

Assim, é somente a partir do encontro com a mãe e dos cuidados por esta oferecidos que o bebê vai recebendo as primeiras inscrições. "Psique e mundo se encontram e nascem um com o outro, um para o outro; são resultado de um estado de encontro que dissemos ser coextensivo ao estado de existente" (Aulagnier, 1975/1979, p. 33). Partindo dessa reflexão proposta pela autora, pode-se afirmar que, nesse primeiro momento, a mãe seria a representante do mundo e vai, aos poucos, oferecendo-o em pequenas doses ao bebê que acaba de chegar.

Segundo Winnicott (1945/2000, p. 224),

na vida normal do bebê ocorrem longos períodos de tempo nos quais o bebê não se importa de ser uma porção de pedacinhos ou um único ser, nem se ele vive no rosto da mãe ou em seu próprio corpo, desde que de tempos em tempos ele se torne uno e sinta alguma coisa.

Ou seja, é somente a partir da contenção oferecida pelos braços maternos, pela experiência de alimentação e satisfação, pelos cuidados oferecidos ao corpo do bebê, que este pode, ainda que por pouco tempo, em se tratando do início da vida, viver a experiência de integração.

A adaptação ao mundo externo - que denominarei de "aéreo" ao longo deste trabalho - dependerá, sobretudo, da capacidade adaptativa da mãe às demandas específicas e particulares de seu bebê. E é somente a partir de um sem número de experiências que este aprenderá sobre o tempo, marcado e representado pelas idas e vindas da mãe, adquirindo recursos, ao longo desse processo, para suportar as ausências. Vemos, assim, como a partir das experiências vividas com a mãe o bebê vai, aos poucos, se organizando e encontrando sentido nas experiências, que ganham sentido e significado a partir da nomeação materna.

Ao entrarmos em contato com a necessidade de dependência absoluta em relação à figura materna que o bebê precisa vivenciar, é inevitável refletirmos sobre o lugar da mãe e a exigência, tanto física quanto psíquica, de adaptação desta às necessidades do filho que acaba de nascer. Ao buscarmos compreender tais exigências, tanto do ponto de vista do bebê quanto do da mãe, vamos nos 
aproximando da ideia de que a chegada do bebê traz inúmeras dificuldades que precisarão ser acolhidas e mais profundamente compreendidas.

Nesse sentido, faz-se necessário separar instinto de adoção - que pode ser compreendida pela capacidade da mãe de acolher genuinamente seu bebê. Como afirma Badinter (1980/1985) “em vez de instinto, não seria melhor falar de uma fabulosa pressão social para que a mulher só possa se realizar na maternidade?" (p. 355).

Vamos, dessa forma, nos afastando dos instintos e nos aproximando dos aspectos históricos e inconscientes que se atualizam com o nascimento de uma criança. Tais reflexões nos permitem observar que a chegada do bebê, para além daquilo que é comumente descrito como esperança, alegria, amor incondicional, também traz consigo elementos que nos remetem a loucura e catástrofe, vida e morte, linguagem e impossibilidade de comunicação - paradoxos do encontro e de possíveis desencontros.

Winnicott (1956/2000) descreve o estado emocional da mãe no pós-parto como uma "loucura saudável" - estado que lhe permite consagrar-se exclusivamente ao bebê. Ao descrever esse estado em que a mãe devota os cuidados ao filho, o autor parece justificar o aforismo freudiano sobre a continuidade intrauterina e a primeira infância. Nesse estado, denominado de "preocupação materna primária", o bebê, para a mãe, é o bebê do narcisismo primário freudiano (desejo materno de que seu bebê seja o mais maravilhoso de todos). Lebovici (1983/1987, p. 216) atenta, no entanto, para o fato de que

quando esta mãe é jovem e primípara, ela fica muitas vezes inquieta por ter de enfrentar esta criança viva e exigente.... Certamente, as condições da gestação e do nascimento, sua aceitação ou sua recusa contribuem para as diversas modulações do que não sempre é um estado de graça.

As dificuldades maternas frequentemente observadas no início da vida do bebê e, no limite, as patologias que se manifestam nas mães, como as anteriormente mencionadas, permitem-nos pensar sobre a radicalidade observada na mudança de condição pela qual o bebê deve passar para vir à luz - do útero materno, que podemos denominar de "mundo aquático", para o exterior, "mundo aéreo" - suscetível ao estado emocional da mãe, absolutamente dependente e ainda sem recursos para se comunicar. Além disso, é preciso que mãe e filho se adaptem, um ao outro, que encontrem, na medida do possível, uma sintonia e um modo de comunicação. Como afirma Stern (1995/1997, p. 28), do ponto de vista da mãe, "o nascimento é o local de encontro do bebê agora em seus braços com aquele que está em sua mente".

Sem possibilidade de comunicar verbalmente o que sente e o que o incomoda, o bebê pode ser compreendido a partir de seu estatuto de 
estrangeiro. Estrangeiro, pois, impossibilitado de se comunicar fazendo uso da linguagem, precisa encontrar recursos em seu próprio corpo e no corpo da mãe, do qual agora está separado, para sobreviver e se relacionar. Podemos, dessa forma, considerar esse bebê como familiar e, ao mesmo tempo, enigmático, tão próximo e tão distante, marcado pelo humano que o caracteriza. Bebê que provoca, em seu entorno, na mãe e nos cuidadores, encantamento e terror, alegrias e tristezas, medo e coragem. Tais ambivalências parecem, assim, relevantes para pensarmos o início da vida.

Winnicott (1947/2000) é categórico ao afirmar que a mãe odeia seu bebê desde o início. O autor questiona, inclusive, a possibilidade de Freud achar que a mãe, em determinadas circunstâncias, sentisse somente amor pelo filho do sexo masculino - "Mas disto podemos duvidar. Conhecemos o amor de mãe e o admiramos por ser tão forte e tão real" (Winnicott, 1947/2000, p. 285) - e, em seguida, pede permissão para elencar 23 razões para uma mãe odiar seu bebê, ironizando, no final, ao afirmar que está ciente de que existem muito mais motivos.

Compreender a ambivalência presente na relação da mãe com seu bebê passa pelo fato de que é preciso reconhecer que todo bebê, ao vir à luz, porta consigo um enigma, e sua chegada suscita a elaboração de diversas perguntas: quem é esse bebê, com quem se parece, como acolhê-lo 
e como compreender suas dificuldades. Além disso, ao refletirmos sobre o Narcisismo Primário freudiano, é inevitável vermos, no discurso e nas questões levantadas pelos pais, o desejo de que todas as dificuldades vividas por eles na infância, assim como todos os desejos irrealizáveis por eles até então, serão "recuperados" ou "corrigidos" através do filho que acaba de nascer.

Tais questões parecem representar um trabalho de busca pelo ponto zero - o ponto inicial presente em cada um de nós. Nas palavras de Freud (1914/2010, p. 37),

No ponto mais delicado do sistema narcísico, a imortalidade do eu, tão duramente acossada pela realidade, a segurança é obtida refugiando-se na criança. O amor dos pais, comovente e no fundo tão infantil, não é outra coisa senão o narcisismo dos pais renascido, que na sua transformação em amor objetal revela inconfundivelmente a sua natureza de outrora.

A afirmação freudiana coloca-nos em contato com a rede de fantasias e protofantasias presentes no momento do nascimento. Sonhado, falado e fantasiado antes de sua chegada, o bebê real precisa se apresentar, ser acolhido e visto pelos pais. Mais uma vez, sua condição de desconhecido, de estrangeiro, precisa ser ressignificada para que a condição de sujeito possa se instalar. Para tanto, como afirma Stern (1995/1997), a mãe precisa elaborar o fato de que não será mais possível 
retornar à própria infância, abandonando suas fantasias relacionadas a esse tempo de sua vida: "Ela talvez possa reparar o passado, mas jamais como uma menina novamente" (p. 29).

O caráter de estrangeiro pode ser compreendido se levarmos em consideração a mudança de condição da vida aquática e chegada ao mundo aéreo: bebê manipulado, carregado, levado de um lugar a outro. Sem autonomia, impossibilitado de se comunicar, vive a experiência da falta de gravidade ao "voar", sem controle do próprio corpo, de um colo a outro: "ser quase totalmente desamparado, ainda desorientado no mundo, que acolhe estímulos no seu tecido nervoso" (Freud, 1915/2010, p. 54). Bebê que irá orbitar em torno da mãe (ou é a mãe que orbita ao redor do filho? "His majesty, the baby"). A observação atenta disso que podemos denominar de coreografia interativa nos oferece elementos para compreendermos e acolhermos a complexidade presente no início da vida.

A partir de tais constatações, pode-se afirmar que uma mãe com condições de se disponibilizar para seu bebê, atendendo-o na medida de suas necessidades, vai oferecendo e permitindo a este o acesso à sensação de gravidade, até então desconhecida. Em contraposição a isso, Winnicott (1952/2000), ao falar sobre as falhas maternas e suas consequências, usa como imagem a sensação, experimentada pelo bebê, de "cair para sempre".

Os registros mnêmicos desse tempo marcam o corpo, tatuagens invisíveis de uma história que se inicia. Na linguagem do corpo observamos aquilo que não pôde ser expresso em linguagem simbólica, aspectos da organização psíquica primitiva, que Winnicott (1952/2000) denomina de terrores extremos, sem fim, sem limites - angústias impensáveis, uma vez que não há psiquismo organizado minimamente para pensá-las.

Nesse sentido, compreende-se a importância da disponibilidade e sensibilidade materna para viabilizar a chegada e a introdução do bebê ao mundo externo. A maneira como a mãe apresenta o mundo a esse bebê que chega nos diz sobre os primeiros acordes de comunicação dessa díade. Como afirma Winnicott (1945/2000), pode-se dizer que a mãe ajuda o bebê a perceber o mundo em pequenas doses.

A sensibilidade e adaptação maternas permitem ao bebê sobreviver à angústia presente na condição de desamparo experimentada no ato do nascimento. 
Nos dois aspectos, como fenômeno automático e como sinal salvador, a angústia revela-se produto do desamparo psíquico do bebê, que é a contrapartida evidente de seu desamparo biológico. Não requer interpretação psicológica a notável coincidência de que tanto a angústia do nascimento como a angústia do bebê são determinadas pela separação da mãe (Freud, 1926/2014, p. 80).

Observamos, já em Freud, uma atenção especial, no que se refere ao início da vida, marcado, sobretudo, pela separação da mãe: nas palavras de Otto Rank, trauma do nascimento.

Assim, a partir da condição de desamparo e, ao mesmo tempo da presença materna, vamos nos aproximando desse sentido que podemos denominar de órbita mútua: bebê e mãe, que se atraem, se afastam, buscam formas e sentidos de comunicação: uma mãe que fala, canta, relata, conta, descreve, projeta. E um bebê que necessita de contato e cuidado para que, no limite, possa sobreviver. Observamos, nessa relação de encantamento e dificuldades, uma dupla tentando se conhecer e comunicar: movimentos e formas que vão desenhando a organização psicossomática de um ser frágil, dependente, à mercê do outro.

A condição de desamparo psíquico e falta de unidade corporal - características marcantes do recém-nascido - aparecem, dentre outros aspectos, pela capacidade visual limitada do bebê, pela caixa craniana aberta, pela impossibilidade de mobilidade e articulação motora. O bebê, ao nascer, precisa de tempo para ajustar o sentido da visão. Não enxerga a mais de 20 centímetros de distância: o suficiente para reconhecer o rosto da mãe, quando posicionado nos braços dela para ser amamentado.

Assim, compreende-se que o elemento de tridimensionalidade não atua na organização psicossomática do bebê, que ainda não possui aparato físico ou psíquico para enxergar o que está atrás, ou para além da mãe. "Poderíamos argumentar que desenvolvitalmente a díade é a unidade mais inicial e mais básica. O apego é diádico, e não triádico; duas pessoas, mas não três, podem olhar nos olhos uma da outra" (Stern, 1995/1997, p. 31).

A afirmação de Stern aproxima-nos da ideia de que, nesse primeiro tempo da vida, a relação primordial com a figura materna absorve toda e qualquer possibilidade de contato. A mãe, quando disponível e atenta às necessidades de seu bebê, representa, para este, fonte de alimentação, cuidado e investimento, funcionando como base para a organização psíquica. Nas palavras de Freud (1940/2014),

o primeiro objeto erótico da criança é o seio que a alimenta; o amor surge apoiado no apaziguamento da necessidade de nutrição. Por certo, o seio não é distinguido inicialmente do próprio corpo e deslocado para "fora", porque a criança com tanta frequência sente sua falta, ele carrega consigo, na qualidade de "objeto", uma parte das cargas libidinais originariamente narcísicas. 
Posteriormente, esse objeto completa-se até formar a pessoa total da mãe, que não apenas alimenta, mas também dela cuida e, assim, desperta na criança tantas outras sensações corporais, prazerosas e desprazerosas. Através dos cuidados com o corpo, ela se torna a primeira sedutora da criança. Nessas duas relações enraíza-se o singular e incomparável significado da mãe, fixado de modo inalterável para toda a vida, como o primeiro e mais forte objeto amoroso e como protótipo de todos os relacionamentos amorosos posteriores - para ambos os sexos (p. 128).

A reflexão freudiana sobre a significação da mãe como objeto e protótipo de todas as relações posteriores do humano, associada à fragilidade do bebê, suscita numerosas questões, contribuindo para aumentar o enigma presente na chegada do bebê ao mundo, assim como um desejo (tanto por parte da mãe quanto de nós, profissionais interessados pela primeira infância) de desvendá-lo, na tentativa de compreender o que está em jogo nesse encontro: fantasias, projeções, desejo - aspectos da maternidade.

Essa reflexão leva-nos a considerar que, primeiramente, pensamos a partir do outro, do qual somos tão completamente dependentes. Assim, compreende-se que, só mais tarde, seremos capazes de considerar a existência e significação desse outro, simbolizado pela figura materna e, a partir dela, as outras figuras humanas a nossa volta, para depois sermos capazes de enxergar e explorar o mundo.

Para além disso, e o bebê? O que este porta consigo como características que lhe são próprias, singulares e únicas? Seu estado de prematuridade e inacabamento já nos é evidente e vem sendo, juntamente com as competências que lhe são próprias, há muito estudados. O reconhecimento da voz materna, sua capacidade de seguir atentamente os movimentos da mãe, exercícios motores complexos, dentre outros, são exemplos de tais competências observadas e descritas por inúmeros autores (Brazelton, 1984; Cramer, 1993, entre outros) - imagens que nos impressionam, se considerarmos o nível de fragilidade característica do bebê humano.

Parece significativo, no entanto, buscarmos compreender e observar o bebê em sua singularidade - exercício que envolve, necessariamente, a mãe. Afinal, se considerarmos que o bebê não é somente uma tábula rasa, unicamente à espera de receber inscrições e absorver os investimentos do outro, devemos buscar saber o que lhe é próprio, ou talvez, buscar compreender o que esse sujeito traz consigo. Afinal, como afirma Aulagnier (1975/1979, p. 63), “o Eu não está condenado ao desconhecimento, nem é 
uma instância passiva. Ainda que seus primeiros identificados sejam providos pelo discurso materno, o Eu também é uma instância identificante e não é um produto passivo do discurso do Outro".

Por outro lado, Crespin (2004) afirma que a prematuridade que marca o chamado sofrimento primordial caracterizado pelo nascimento - tem profunda relação com o fato de que a sobrevivência do bebê humano não se garante sem ajuda exterior.

Mesmo quando um recém-nascido se encontra em seu estado ótimo de nascimento, quando possui todas as competências de que nos fala Brazelton, ele não tem nenhuma possibilidade de sobreviver sem a ajuda de um semelhante. Sua esperança de vida na ausência de um semelhante é de quatro a cinco horas, se não estiver muito frio (Crespin, 2004, p. 18).

Tal afirmação contribui para compreendermos a complexidade presente na busca por entender a constituição psíquica do bebê uma vez que, como afirma Aulagnier, o bebê não é somente um produto passivo do discurso do outro. Ao mesmo tempo, deve-se considerar a impossibilidade de sobrevivência deste, sem a presença de um adulto que dele se ocupe: observa-se, novamente, o paradoxo característico desse tempo da vida.

É relevante nos atermos ao fato de que, ao falarmos sobre nascimento psíquico, é inevitável nos remetermos à questão das origens (do bebê, dos pais, e, no limite, daquilo que é próprio 
e singular a cada criança que nasce) e aceitarmos o fato de que o mistério presente no início da vida, ou naquilo que nos origina, funda e traz à luz, permanece.

Deve-se considerar também que as experiências iniciais- arcaicas e primitivas - estão presentes e se atualizam no humano, mas temos dificuldade de acessá-las. Talvez por isso mesmo seja tão complexo colocar em palavras e significar esse início da vida: tempo em que, como propõe Aulagnier (1975/1979, p. 19) somos impelidos a nos confrontarmos com um discurso que não deixa espaço para a dúvida,

que opõe a certeza do delírio à lógica da nossa razão e lhe sugere que houve um tempo longínquo no qual ela também encontrou um discurso que se impunha como detentor exclusivo da verdade. Discurso a serviço de uma violência tão radical quanto necessária, única a permitir o acesso ao patrimônio partilhado que é a linguagem.

Ao mergulharmos no interior dessa relação complexa e única, que envolve a mãe, com sua própria história e experiências não simbolizadas e o bebê que a coloca em contato, justamente com esses aspectos primitivos, vamos nos aproximando da necessidade de aprofundarmos nossa compreensão acerca desse período, em uma tentativa de aproximação e compreensão de aspectos presentes no início da vida. Tal tarefa parece complexa e desafiadora, justamente por se tratar de um tempo em que as fragilidades, físicas e psíquicas, estão expostas. Aproximar-se eticamente da díade mãe-bebê, sem que essa aproximação se constitua também em uma violência, exige atenção. Além disso, deve-se considerar que aspectos psíquicos primitivos do próprio observador também se atualizam e presentificam. Nesse sentido, a violência da interpretação proposta por Aulagnier estará, inevitavelmente presente.

Importante salientar, no entanto, que a autora é categórica ao afirmar que essa violência, denominada de primária, é necessária, pois é responsável por inserir o sujeito na ordem humana. Vemos, assim, a complexidade presente na interação dessa díade e as sutilezas a serem observadas com cuidado. Fundamental levarmos em consideração o fato de que a familiaridade entre o bebê e sua mãe irá se construir pouco a pouco. Além disso, deve-se levar em conta as dificuldades de se falar sobre um tempo da vida no qual as palavras ainda não existem, ou melhor, ainda não passaram por um sistema de representação para que possam ser significadas.

Compreende-se, dessa forma, que a ausência de linguagem verbal contribui para a estranheza causada pelo bebê, que provoca, por parte do adulto que dele se ocupa, grande esforço para decifrá-lo, grande esforço de interpretação e, ao mesmo tempo, nos remete ao que está inscrito em nós, mas que não pode ser recuperado, justamente por tratar-se de experiências que nunca passaram pela inscrição da linguagem. 


\section{Abstract}

This article aims to discuss aspects related to the encounter mother-baby in the post-delivery moments. The birth and the reception of the new baby are, in general, described by the mother as a moment of joy and the feeling of completeness. Considering that we hardly observe that the difficulties of this period comes up in the mother's speech, our proposal is to discuss what is behind the difficulties of the mothers in communicating the pain and the difficulties that are also part of this moment. Therefore, we intend to look at the psychoanalytical aspects related to the psychological organization of the baby's mind, in order to understand the complexity present at birth, in the mother's point of view, as well as the baby's. In order to do that, we intend to locate at the Frendian works, the moments when the author presents, in his theory, the importance of the mother-unique and essential, responsible for receiving the baby and offering her own ego to the newborn. We also intend to observe the development of these thoughts in the post-Freudian authors.

Index terms: mother-baby; post-partum depression; ambivalence.

\section{ENCUENTROS Y DESENCUENTROS: DEL NASCIMIENTO A LA CONSTITUCIÓN DE LA PSIQUE}

\section{Resumen}

Este texto tiene como objetivo discutir aspectos relacionados con el posparto y el encuentro madre-bebé. El nacimiento y la recepción del bebé que llega son descritos generalmente por su madre como un momento de profunda alegría y el sentimiento de plenitud. Suponiendo que las dificultades vividas difícilmente surgen en el discurso materno, hemos propuesto discutir lo que está detrás de la negación del dolor y de las dificultades, que también están presentes en este momento. Nuestra intención es reanudar aspectos del pensamiento psicoanalitico en relación con la constitución y la organización de la psique del bebé con el fin de comprender más la complejïdad presente en el nacimiento, del punto de vista del bebé y también de la madre. Por lo tanto, tenemos la intención de reanudar el texto freudiano, los momentos en los que el autor presenta la importancia de la figura materna -figura única y esencial, responsable del cuidado y también de ofrecerle su ego al bijo que llega. Por otra parte, se reanudaron de autores posfreudianos avances psicoanalíticos en esta área.

Palabras clave: madre-bebé; depresión posparto; ambivalencia.

\section{REFERÊNCIAS}

Aulagnier, P. (1979). A violência da interpretação: do pictograma ao enunciado (M. C. G. Pellegrino, trad.). Rio de Janeiro, RJ: Imago. (Trabalho original publicado em 1975)

Badinter, E. (1985). Um amor conquistado: o mito do amor materno (W. Dutra, trad.). Rio de Janeiro, RJ: Nova Fronteira. (Trabalho original publicado em 1980)

Brazelton, T. B. (1984). To listen to a child. Reading, MA: Addison Wesley.

Coutinho, A. H. S. A. (2009). Sonhos, angústia e alienação. Reverso, 31(58), 53-62.

Cramer, B. (1993). Mother-baby interactions: in reality and in fantasy. In Anais, 3. International Psychoanalytic Association Standing Conference on Psychoanalytic Research: the observed child and the reconstructed child (pp. 88-95), 1993. London.

Crespin, G. (2004). A clínica precoce: o nascimento do humano (C. M. F. Rohenkohl, M. A. Fernandes, M. C. Camarotti, \& R. O. Aragão, trad.). São Paulo, SP: Casa do Psicólogo. 
Eliacheff, C. (1995). Corpos que gritam: a Psicanálise com bebês (S. Goldfeder, trad.). São Paulo, SP: Ática. (Trabalho original publicado em 1993)

Faria, T. M. S. (2010). A sombra e a constituição do Eu em Piera Aulagnier. Mosaico: Estudos em Psicologia, 4(1), 1-8.

Freud (1996). A interpretação dos sonhos. In S. Freud, Edição standard brasileira das obras psicológicas de Sigmund Freud (J. Salomão, trad., Vol. V, pp. 3-229). Rio de Janeiro, RJ: Imago. (Trabalho original publicado em 1900)

Freud, S. (1996). Três ensaios sobre a teoria da sexualidade. In S. Freud, Edição standard brasileira das obras psicológicas de Sigmund Freud (J. Salomão, trad., Vol. VII, pp. 20-172). Obras Completas: Edição Standard Brasileira. Vol. VII Rio de Janeiro, RJ: Imago. (Trabalho original publicado em 1905)

Freud, S. (2010). Introdução ao narcisismo. In S. Freud, Sigmund Freud: obras completas (P. C. Sousa, trad., Vol. 12, pp. 13-59). São Paulo, SP: Companhia das Letras. (Trabalho original publicado em 1914)

Freud, S. (2010). Os instintos e seus destinos. In S. Freud, Sigmund Freud: obras completas (P. C. Sousa, trad., Vol. 12, pp. 52-81). São Paulo, SP: Companhia das Letras. (Trabalho original publicado em 1915)

Freud (2014). Inibição, sintoma e angústia. In S. Freud, Sigmund Freud: obras completas (P. C. Sousa, trad., Vol. 17, pp. 14-123). São Paulo, SP: Companhia das Letras. (Trabalho original publicado em 1926)

Freud, S. (2014). Compêndio de Psicanálise e outros escritos inacabados (P. H. Tavares, trad.). São Paulo, SP: Autêntica. (Trabalho original publicado em 1940)

Golse, B. (2003). Sobre a Psicoterapia pais-bebê: narratividade, filiação e transmissão (I. Catão, M. A. Fernandes, J. Castilho, R. Aragão, \& C. M. F. Rohenkohl, trad.). São Paulo, SP: Casa do Psicólogo

Kanner, L. (1979). Psiquiatria infantil. Buenos Aires: Siglo Veinte. (Trabalho original publicado em 1943)

Lacroix, M.-B., \& Monmayrart, M. (1997). A observação de bebês: os laços do encantamento (F. F. Settineri, trad.). Porto Alegre, RS: Artes Médicas. (Trabalho original publicado em 1995)

Lebovici, S. (1987). O bebê, a mãe e o psicanalista (F. Vidal, trad.). Porto Alegre, RS: Artes Médicas. (Trabalho original publicado em 1983)

Rennó, C. (2012). De onde vêm os analistas? Do umbido do sonho! Recuperado de http://bit. ly/2lQkfnm

Spitz, R. (1999). O primeiro ano de vida (V. L. B. Sousa, \& I. Rizzini). São Paulo, SP: Martins Fontes. (Trabalho original publicado em 1950).

Stern, D. N. (1997). A constelação da maternidade (M. A. V. Varonese, trad.). Porto Alegre, RS: Artes Médicas. (Trabalho original publicado em 1995)

Winnicott, D. W. (2000). Desenvolvimento emocional primitivo. In D. W. Winnicott, Da pediatria à psicanálise (D. Bogomoletz, trad., pp. 218-232). São Paulo, SP: Imago. (Trabalho original publicado em 1945)

Winnicott, D. W. (2000). O ódio na contratransferência Desenvolvimento emocional primitivo. In D. W. Winnicott, Da pediatria à psicanálise (D. Bogomoletz, trad., pp. 277-287). São Paulo, SP: Imago. (Trabalho original publicado em 1947)

Winnicott, D. W. (2000). Memórias do nascimento, trauma do nascimento e ansiedade. In D. W. Winnicott, Da pediatria à psicanálise (D. Bogomoletz, trad., pp. 254-276). São Paulo, SP: Imago. (Trabalho original publicado em 1949) 
Winnicott, D. W. (2000). Psicoses e Cuidados Maternos. In D. W. Winnicott, Da pediatria à psicanálise (D. Bogomoletz, trad., pp. 305-315). São Paulo, SP: Imago. (Trabalho original publicado em 1952)

Winnicott, D. W. (2000). A preocupação materna primária In D. W. Winnicott, Da pediatria à psicanálise (D. Bogomoletz, trad., pp. 399-405). São Paulo, SP: Imago. (Trabalho original publicado em 1956)

paulanogueira@hotmail.com

SQS 213, bloco B - apto. 303 70292-020- Brasília - DF - Brasil.

dchatelard@gmail.com SQN 206 - J - 105 70844-100 - Brasília - DF - Brasil.

isalenasc@yahoo.com.br Av. dos Portugueses, s/n, Bacanga, CCHLA, Departamento de Psicologia. 65085-580 - São Luís - MA - Brasil. 